\title{
Structural and Thermal Studies of ZnS and CdS Nanoparticles in Polymer Matrices
}

\author{
Jejenija Osuntokun and Peter A. Ajibade \\ Department of Chemistry, University of Fort Hare, Private Bag X1314, Alice 5700, South Africa \\ Correspondence should be addressed to Peter A. Ajibade; pajibade@ufh.ac.za
}

Received 17 September 2015; Revised 3 November 2015; Accepted 12 November 2015

Academic Editor: Takuya Tsuzuki

Copyright ( $(2016$ J. Osuntokun and P. A. Ajibade. This is an open access article distributed under the Creative Commons Attribution License, which permits unrestricted use, distribution, and reproduction in any medium, provided the original work is properly cited.

\begin{abstract}
We report the synthesis and structural studies of ZnS and CdS nanoparticles in polyvinylpyrrolidone (PVP), poly(vinyl alcohol) (PVA), and poly (methyl methacrylate) (PMMA) matrices. The metal sulfides/polymer nanocomposites were characterized by X-ray diffraction (XRD), Fourier transform infrared spectroscopy, electronic spectroscopy (UV-Vis), transmission electron microscopy (TEM), and thermogravimetric analysis (TGA). The particle sizes as calculated from the absorption spectra were in agreement with the results obtained from TEM and XRD data. They showed metal sulfides nanoparticles in the polymers matrices with average crystallite sizes of $1.5-6.9 \mathrm{~nm}$. The TGA results indicate that incorporation of the nanoparticles significantly altered the thermal properties of the respective polymers with ZnS/PVA and CdS/PVA nanocomposites displaying higher thermal stability than the other polymer nanocomposites.
\end{abstract}

\section{Introduction}

Nanocomposites are the fusion of two or more different materials in which at least one of the components has dimension less than $100 \mathrm{~nm}$ [1]. In polymer nanocomposites, the blends consist of organic polymer matrix and inorganic components (semiconductors). The lack of satisfactory mechanical, thermal, and electronic properties of the conventional polymer materials gave rise to the need to functionalize them in an attempt to improve their properties and extend their potential applications [2, 3]. PMMA, PVA, and PVP are among the most widely used polymers in the synthesis of nanocomposites because of their availability and low cost [4-7]. Among group II-VI compound semiconductors nanoparticles, $\mathrm{ZnS}$ and $\mathrm{CdS}$ are the most promising materials [8]. $\mathrm{ZnS}$ is a good material for detecting ultraviolet and violet radiation due to its primary band gap of $3.68 \mathrm{eV}(345 \mathrm{~nm})$ and high sensitivity. It has potential applications in optics, optoelectronics, and solar energy $[9,10]$. CdS with a direct band gap of $2.42 \mathrm{eV}(515 \mathrm{~nm})$ has applications in window layers [11], light emitting diodes [12], and photodetectors. Its applications in photodetector and solar cells when used in conjunction with narrow band gap materials such as CdTe have been reported [13].

The two common routes for the synthesis of polymer nanocomposites are the ex situ and in situ methods [14-16]. The two methods are liquid based, and the end products are solid which are obtained by either coprecipitation or solvent evaporation [17]. The synthesis of MS/PMMA or PVA or PVP where $\mathrm{M}=\mathrm{Zn}$ or $\mathrm{Cd}$ via different chemical and physical routes has been reported by many authors [18-22]. However, there is no report on comparative studies of the structural properties and thermal stability of the nanocomposites of ZnS/CdS nanoparticles in PMMA, PVA, and PVP. In this work, we investigate the structural and thermal properties of different polymer nanocomposites prepared by the incorporation of $\mathrm{ZnS}$ and $\mathrm{CdS}$ into the matrices of theses polymers: poly(methyl methacrylate) (PMMA), poly(vinyl alcohol) (PVA), and polyvinylpyrrolidone (PVP). The structural studies of the metal sulfides/polymer nanocomposites were carried out by X-ray diffraction (XRD), Fourier transform infrared spectroscopy, ultraviolet-visible spectroscopy (UV-Vis), transmission electron microscopy (TEM), and thermogravimetric analysis (TGA). 


\section{Materials and Methods}

2.1. Materials. Methanol, poly(methyl methacrylate) (PMMA), poly(vinyl alcohol) (PVA), polyvinylpyrrolidone (PVP), and toluene used in this work were all purchased from Merck. All the reagents were of analytical grade and were used as supplied.

2.2. Characterization. The FTIR analysis of the as-prepared polymer composites was performed on a Perkin Elmer Paragon 2000 FTIR spectrophotometer, in the range of 4000$350 \mathrm{~cm}^{-1}$. The thermogravimetric analysis was carried out on SDTQ 600 thermal instrument. About $10-12 \mathrm{mg}$ of samples was heated in an alumina crucible at $10^{\circ} \mathrm{C} \mathrm{min}^{-1}$ within the temperature range of $20-650^{\circ} \mathrm{C}$ under nitrogen atmosphere. Scanning electron microscope images were analysed using JOEL JSM-6390 LVSEM, at different magnifications as shown on the SEM micrograph. Samples for SEM analysis were prepared by mounting the nanoparticles on a stub using carbon double-sided tape. The samples were coated with $\mathrm{Au} / \mathrm{Pd}$ using the Eiko IB-3 ion coater for better imaging. The X-ray diffractogram of the nanoparticles was recorded on a Bruker D8 Advanced, equipped with a proportional counter using $\mathrm{Cu} \mathrm{K} \alpha$ radiation ( $\lambda=1.5405 \AA$, nickel filter). $\mathrm{UV}$-visible spectra of the nanoparticles were recorded using Perkin Elmer Lambda 25 spectrophotometer, in toluene from 200 to $800 \mathrm{~cm}^{-1}$.

\subsection{Experimental}

2.3.1. Synthesis of Nanocomposites. The $\mathrm{ZnS}$ and CdS nanoparticles were synthesized as reported in the literature [23]. The ZnS and CdS nanoparticles in PMMA, PVA, and PVP were prepared by a solution casting method [24]. Laboratory grades PMMA, PVA, and PVP were, respectively, dissolved in toluene and stirred for $2 \mathrm{~h}$, followed by the addition of 8 weight \% of $\mathrm{ZnS}$ or $\mathrm{CdS}$ nanoparticles dissolved in the same solvent and added to the polymers solution. The choice of 8 weight $\%$ is the concentration of modifiers that exhibit appreciable structural and thermal properties necessary for the purpose of this study. The mixture was stirred at $60^{\circ} \mathrm{C}$ for $24 \mathrm{~h}$, to allow the reaction of the nanoparticles with the polymers and poured into petri dishes to give the various nanocomposites. The toluene was allowed to evaporate slowly over a period of $48 \mathrm{~h}$ in dry atmosphere. The film was then removed and dried in the vacuum at $70^{\circ} \mathrm{C}[25,26]$.

\section{Results and Discussion}

3.1. FTIR Spectra Studies. Figure 1(a) shows the overlapped FTIR spectra of pure PMMA and the respective nanocomposites incorporating $\mathrm{ZnS}$ and $\mathrm{CdS}$ nanoparticles. The graphs are rescaled to allow overlapping. Pure PMMA and the corresponding $\mathrm{ZnS}$ and $\mathrm{CdS}$ nanocomposites show a weak band in the range of $3448-3455 \mathrm{~cm}^{-1}$ that is due to stretching vibration of O-H. PMMA exhibits bands around 2952 and
$2823 \mathrm{~cm}^{-1}$ that are assigned to $\mathrm{C}-\mathrm{H}$ asymmetric and symmetric stretching vibrations, respectively. The bending vibrational bands of the methyl group appear around $1490 \mathrm{~cm}^{-1}$ and $1457 \mathrm{~cm}^{-1}$ [27]. Furthermore, there is a sharp and intense band at $1769 \mathrm{~cm}^{-1}$ which is attributed to the stretching vibration of the carbonyl, $\mathrm{C}=\mathrm{O}$. The $\mathrm{ZnS} / \mathrm{PMMA}$ and $\mathrm{CdS} / \mathrm{PMMA}$ nanocomposites showed stretching vibrations that are not really different from the pure PMMA and this is indicative of weak chemical interaction between the host polymer and the nanoparticles. Similar studies about the interaction of PMMA and nanoparticles have been reported by other researchers [28]. HDA was used as a passivating agent for the metal sulfide nanoparticle and peaks in the region of 3181$3336 \mathrm{~cm}^{-1}$ can be ascribed to the N-H stretching of primary amine. These peaks are observable in the infrared absorption spectra of the nanocomposites and it is indicative of the presence of HDA $[29,30]$.

Figure 1(b) presents the overlapped FTIR spectra of pure PVA and the respective composites with $\mathrm{ZnS}$ and $\mathrm{CdS}$ nanoparticles. PVA exhibits a broadband at $3429 \mathrm{~cm}^{-1}$ which is assigned to $\mathrm{O}-\mathrm{H}$ stretching frequency of the hydroxyl group. This band has been shifted to 3425 and $3424 \mathrm{~cm}^{-1}$ in ZnS/PVA and CdS/PVA, respectively. Two bands observed in the pure PVA at 2942, $1755 \mathrm{~cm}^{-1}$ which correspond to $\mathrm{C}-\mathrm{H}$ and $\mathrm{C}=\mathrm{O}$ stretching vibrations, respectively, are found at $2938,1710 \mathrm{~cm}^{-1}$ and $2931,1749 \mathrm{~cm}^{-1}$ in $\mathrm{ZnS} / \mathrm{PVA}$ and $\mathrm{CdS} / \mathrm{PVA}$ polymer nanocomposites. The absorption band at $1646 \mathrm{~cm}^{-1}$ due to $\mathrm{C}=\mathrm{C}$ stretching in the PVA appears at 1659 and $1653 \mathrm{~cm}^{-1}$ in the $\mathrm{ZnS} / \mathrm{PVA}$ and CdS/PVA nanocomposites, respectively. The observation of characteristics bands of PVA in ZnS/PVA and CdS/PVA confirms the interaction between these semiconductor inorganic nanoparticles and PVA. Similar results have also been reported for $\mathrm{ZnS} / \mathrm{PVA}$ [31] and CdS/PVA [32].

The interaction between the nanoparticles and the PVP, host polymer, was also investigated. Figure 1(c) shows the overlapped spectra of PVP and their respective nanocomposites. In the FTIR spectrum of PVP, the band at $1681 \mathrm{~cm}^{-1}$ is due to the $\mathrm{C}=\mathrm{O}$ stretching mode and after the formation of $\mathrm{ZnS} / \mathrm{PVP}$ and CdS/PVP nanocomposites the $\mathrm{C}=\mathrm{O}$ stretching band appears at 1663 and $1641 \mathrm{~cm}^{-1}$. The red shift of 17 and $40 \mathrm{~cm}^{-1}$, respectively, indicates a strong interaction between the nanoparticles and the PVP host. The band in the region of $1500-1300 \mathrm{~cm}^{-1}$ is fairly strong and this is because of the contribution from the in-plane $\mathrm{C}-\mathrm{H}$ bending of different$\mathrm{CH}_{2}$ and- $\mathrm{CH}$ moieties. Most likely the $\mathrm{C}-\mathrm{H}$ bending modes are coupled with $\mathrm{C}-\mathrm{N}$ stretching modes. The existence of strong interactions between $\mathrm{ZnS}$ and CdS with PVP has also been reported before $[33,34]$.

3.1.1. Thermal Analysis of PMMA and Nanocomposites. The thermogravimetric analysis (TGA) of the pure PMMA, the $\mathrm{ZnS} / \mathrm{PMMA}$, and CdS/PMMA nanocomposites is presented in Figures 2(a)-2(c), respectively. The thermal degradation of PMMA occurs in three stages, as inferred from the DTG graph. The degradation of PMMA usually begins with the initiation at the weak head-to-head linkage at $171.12^{\circ} \mathrm{C}$ [35], 


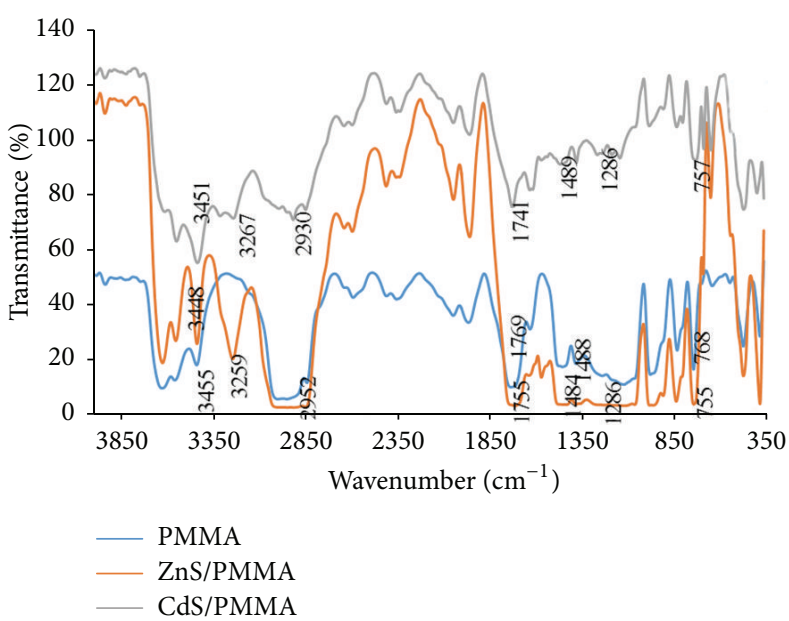

(a)

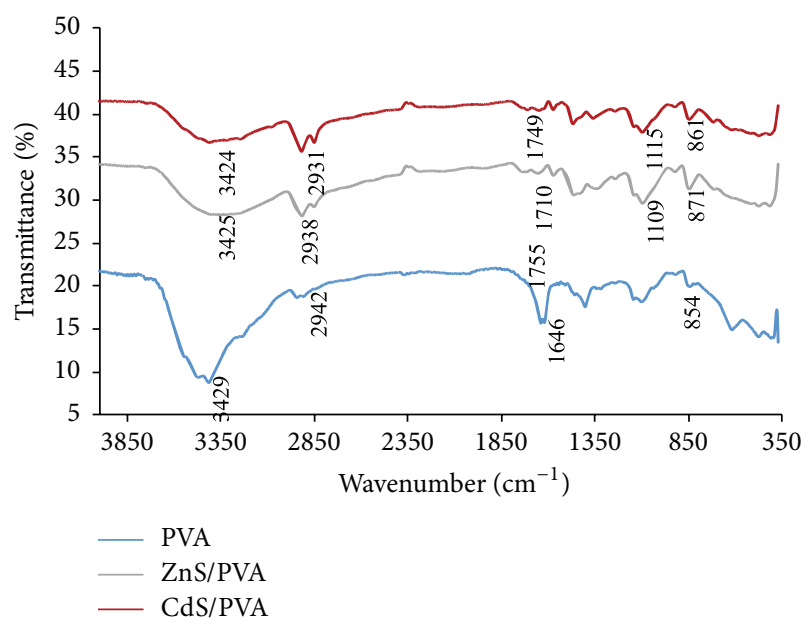

(b)

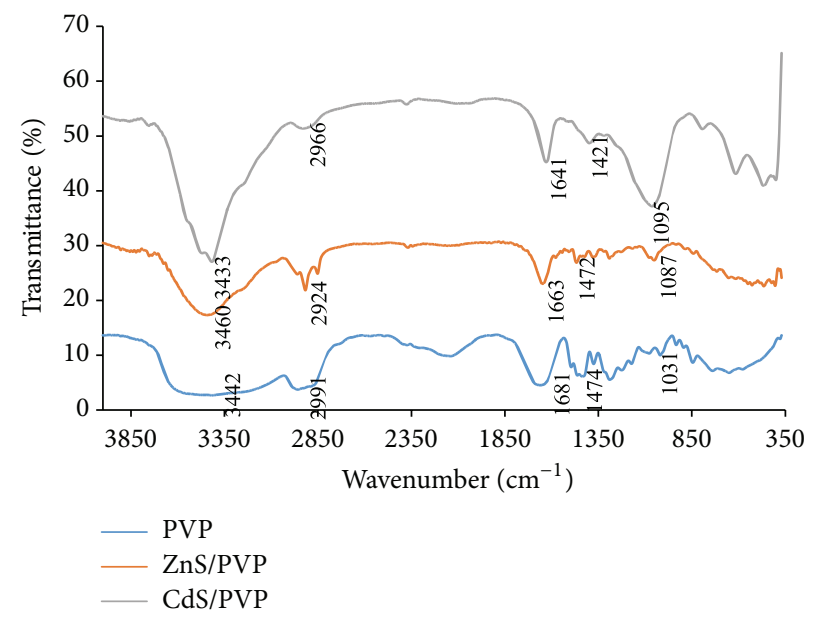

(c)

FIGURE 1: FTIR spectra of (a) pure PMMA, ZnS/PMMA, and CdS/PMMA, (b) pure PVA, ZnS/PVA, and CdS/PVA, and (c) pure PVP, $\mathrm{ZnS} / \mathrm{PVP}$, and CdS/PVP.

and this has been observed in Figure 2(a). Hence the first stage of weight loss is due to the head-to-head scission of the unsaturated end group [36]. The last two degradations occurred at $286.94^{\circ} \mathrm{C}$ and $363.32^{\circ} \mathrm{C}$ which can be ascribed to the initiation at the unsaturated end and at the polymer backbone, respectively [37]. The nanocomposites, ZnS/PMMA and CdS/PMMA, displayed different degradation temp from the pure polymer, Figures 2(b) and 2(c). The temperature of maximum decomposition of the last stage which appeared in pure PMMA at $363.32^{\circ} \mathrm{C}$ occurred at 374.25 and $375.89^{\circ} \mathrm{C}$ in $\mathrm{ZnS} / \mathrm{PMMA}$ and CdS/PMMA, respectively. The major weight loss in PMMA occurred within the range of $180-380^{\circ} \mathrm{C}$ which is in agreement with the structural decomposition of the polymer [36]. On the other hand, the decomposition of $\mathrm{ZnS} / \mathrm{PMMA}$ nanocomposites occurred over the range of 180$420^{\circ} \mathrm{C}$ and $180-425^{\circ} \mathrm{C}$ for the CdS/PMMA nanocomposites. The DSC shows three endothermic peaks in pure PMMA which correspond to three degradation stages while two endothermic peaks are shown in ZnS/PMMA and only one is shown in CdS/PMMA. Thus, the thermal stability of both polymer nanocomposites is greater than that of the pure polymer matrix. The thermal stability of the PMMA has been improved by the incorporation of $\mathrm{ZnS}$ and $\mathrm{CdS}$ separately into the polymer matrix.

3.1.2. Thermal Analysis of PVA and Nanocomposites. Figures 3(a)-3(c) present the overlapped TGA and DTG curves of the pure PVA, ZnS/PVA, and CdS/PVA nanocomposites. There are three stages of weight loss in the degradation pattern of the pure PVA. The earliest one which is between 80 and $220^{\circ} \mathrm{C}$ is attributed to the evaporation of physically weak and chemically bound water [38]. The maximum rate of decomposition of this first stage is at $210^{\circ} \mathrm{C}$, under the experimental conditions. It corresponds to a $28 \%$ weight loss. The second decomposition step is in the temperature range of 230 to $430^{\circ} \mathrm{C}$, causing a total weight loss of about $80 \%$ 


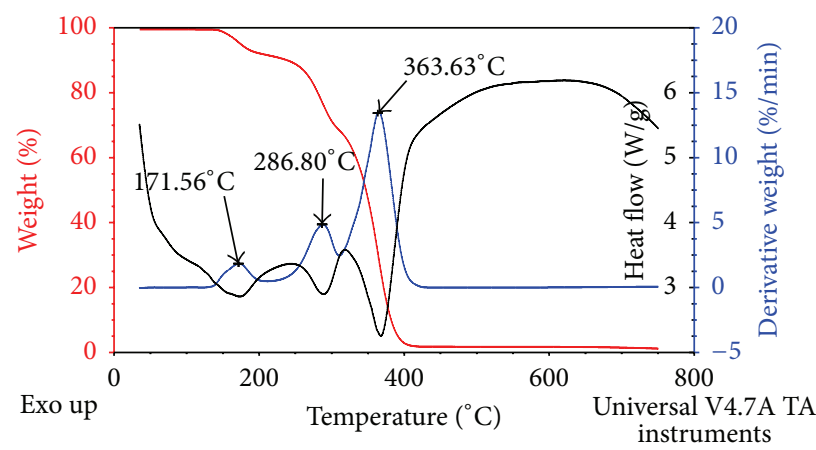

(a)

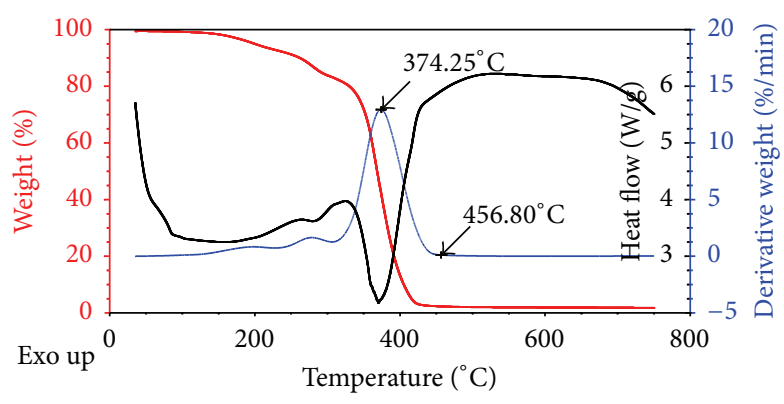

(b)

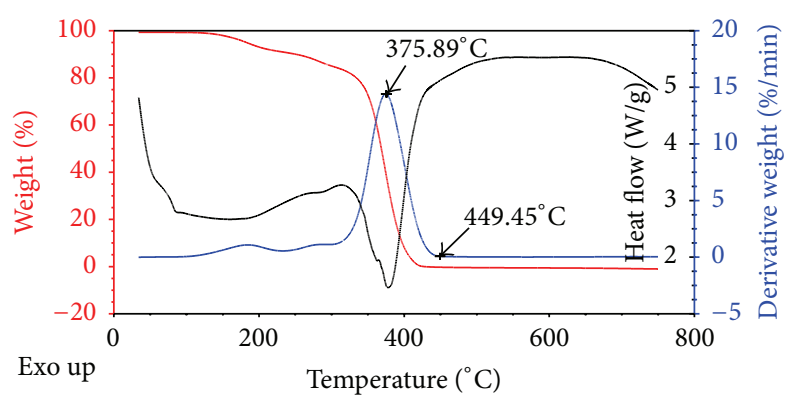

(c)

Figure 2: Overlapped TGA, DTG, and DSC of (a) pure PMMA, (b) ZnS/PMMA, and (c) CdS/PMMA.

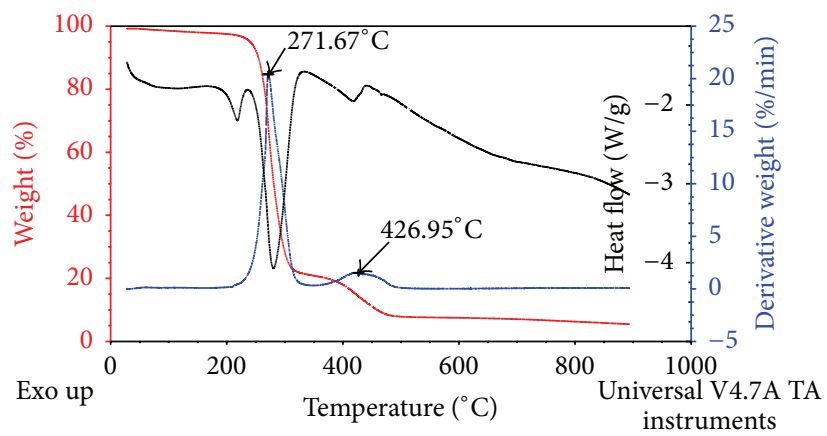

(a)

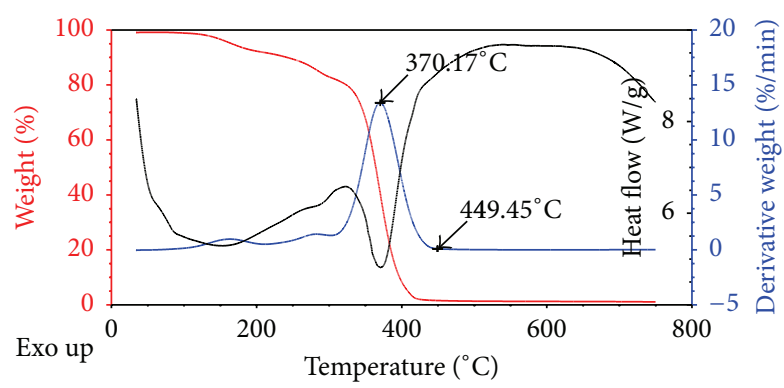

(b)

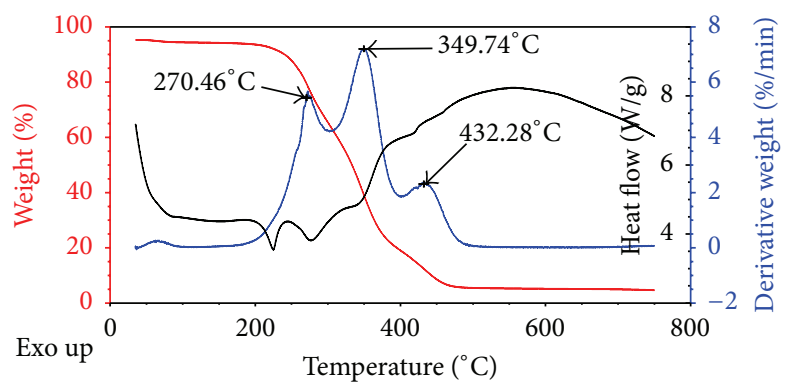

(c)

Figure 3: Overlapped TGA, DTG, and DSC of (a) pure PVA, (b) ZnS/PVA, and (c) CdS/PVA. 


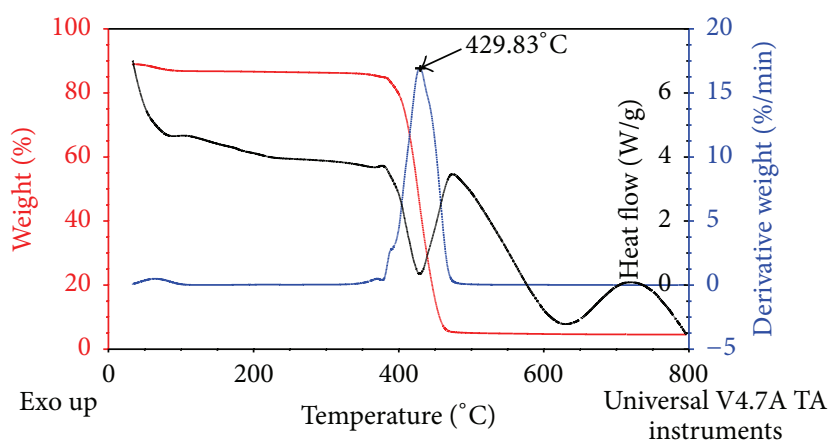

(a)

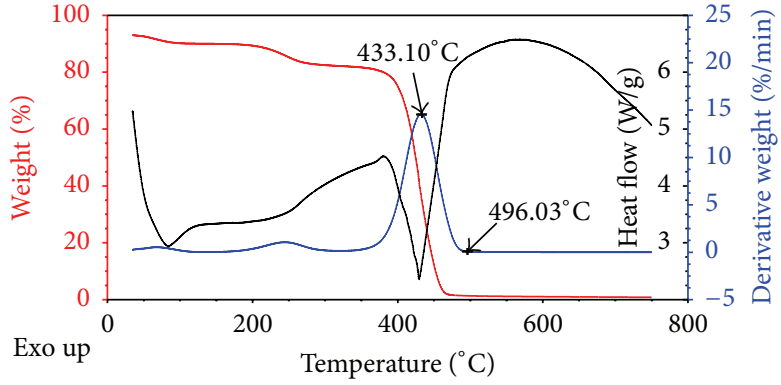

(b)

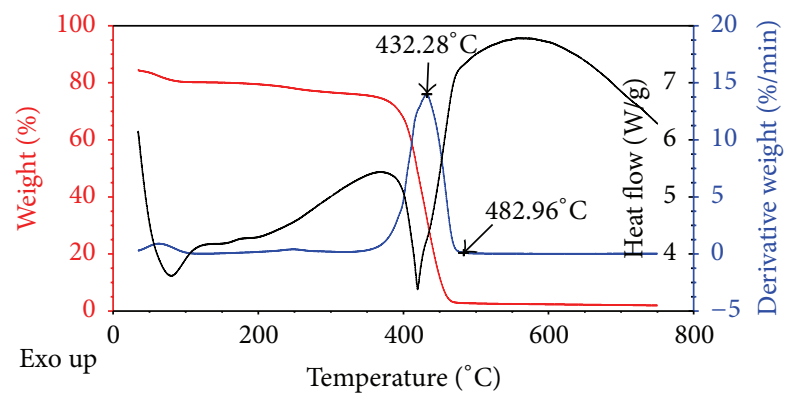

(c)

Figure 4: Overlapped TGA, DTG, and DSC of (a) pure PVP, (b) ZnS/PVP, and (c) CdS/PVP.

and the maximum rate of decomposition is $271^{\circ} \mathrm{C}$. The final decomposition temperature occurred in the range of 410 to $500^{\circ} \mathrm{C}$ with peak at $426^{\circ} \mathrm{C}$, and this is assigned to the cleavage of the C-C pillar of the PVA [39]. The ZnS/PVA degradation pattern is different from that of the pure PVA; only two major decomposition stages occurred. The temperature of the highest rate of decomposition observed at $271^{\circ} \mathrm{C}$ in the pure polymer occurred at around $370^{\circ} \mathrm{C}$ in the nanocomposites. This indicates an enhanced thermal stability with about $100^{\circ} \mathrm{C}$. A plateau occurred at $449^{\circ} \mathrm{C}$ indicating the end of the decomposition, which is about $26^{\circ} \mathrm{C}$ higher when compared with the temperature recorded for pure PVA. In the TGA curve of CdS/PVA, there are 4 stages of decomposition. The first decomposition occurred in the range 40 to $80^{\circ} \mathrm{C}$, and this can be attributed to the expulsion of chemically bound water [40]. This was followed with 3 decomposition steps with peaks at 270,349 , and $432^{\circ} \mathrm{C}$, respectively. After the last decomposition, approximately $60 \%$ weight loss occurred in the nanocomposites with enhanced thermal stability.

3.1.3. Thermal Analysis of PVP and Nanocomposites. Figures 4(a)-4(c) show the overlapped TGA-DTG graph of pure PVP and the corresponding nanocomposites. There are two stages of decomposition in the pure PVP as can be inferred from the differential thermal gravimetric (DTG) curve. The first decomposition step which occurred between 50 and $100^{\circ} \mathrm{C}$ with slight weight loss can be attributed to the evaporation of physically trapped moisture [41]. The decomposition of the PVP commenced at $350^{\circ} \mathrm{C}$ and ended at $480^{\circ} \mathrm{C}$, accompanied with about 95\% weight loss [42]. There appeared complete decomposition of the PVP occurring at $429^{\circ} \mathrm{C}$ and it is accompanied with single DSC endothermic peak maximum at $282^{\circ} \mathrm{C}$ [43]. The TG and DTG curves of $\mathrm{ZnS} / \mathrm{PVP}$ are similar to the pure PVP, with two stages of decomposition but with enhanced thermal decomposition temperature observed at $433^{\circ} \mathrm{C}$. This could be ascribed to the effect of the incorporation of $\mathrm{ZnS}$ in the matrices of the PVP and good interaction between PVP and the ZnS nanoparticles. The composite shows a major weight loss of about $74 \%$ between 410 and $470^{\circ} \mathrm{C}$. The TG and DTG of CdS/PVP show a slight variation from that of pure PVP with a decomposition peak at $433^{\circ} \mathrm{C}$. It also displayed a significant weight loss of approximately $72 \%$ in the temperature range of $390-467^{\circ} \mathrm{C}$. The DTG peak maximum for the $\mathrm{ZnS} / \mathrm{PVP}$ and $\mathrm{CdS} / \mathrm{PVP}$ is $433^{\circ} \mathrm{C}$ and $432^{\circ} \mathrm{C}$ compared to $429^{\circ} \mathrm{C}$ of the pure PVP. The TGA curves of the $\mathrm{ZnS} / \mathrm{PVP}$ and CdS/PVP maintain a plateau from $496^{\circ} \mathrm{C}$ and $483^{\circ} \mathrm{C}$, respectively, due to the complete decomposition of the volatile part of PVP leaving the metal sulfide and negligible weight of the stable substrate as the final residue.

The results obtained from the TGA and DTG show that the interactions of the $\mathrm{ZnS}$ and $\mathrm{CdS}$ nanoparticles with the polymers enhance thermal stability of the resulting polymer nanocomposites. This is deduced from the data obtained when the decomposition temperatures of the nanocomposites are relatively compared with the variation in the decomposition temperature of their respective pure polymers. The summary of this is presented in Table 1 . The sequence of thermal stabilities as a result of the incorporation of 
TABLE 1: Summary of decomposition temperatures of nanocomposites relative to variation in the decomposition of their respective pure polymers.

\begin{tabular}{|c|c|c|c|}
\hline Nanocomposites & $\begin{array}{c}\text { DTG } \\
\text { decomposition } \\
\text { peak max }\left({ }^{\circ} \mathrm{C}\right)\end{array}$ & $\begin{array}{c}\text { Decomposition } \\
\text { temperature range } \\
\left({ }^{\circ} \mathrm{C}\right)\end{array}$ & $\begin{array}{c}\text { Extent of enhanced } \\
\text { thermal stability of } \\
\text { nanocomposites } \\
\left({ }^{\circ} \mathrm{C}\right)\end{array}$ \\
\hline ZnS/PMMA & 374 & $320-457$ & 9 \\
\hline CdS/PMMA & 376 & $340-449$ & 12 \\
\hline $\mathrm{ZnS} / \mathrm{PVA}$ & 370 & $330-449$ & 98 \\
\hline CdS/PVA & 350 & $270-432$ & 78 \\
\hline $\mathrm{ZnS} / \mathrm{PVP}$ & 433 & $360-496$ & 3 \\
\hline CdS/PVP & 432 & $370-482$ & 7 \\
\hline
\end{tabular}

the nanoparticles in the polymer matrices is in the following order: ZnS/PVA > CdS/PVA > CdS/PMMA > ZnS/PMMA > CdS/PVP > ZnS/PVP.

\subsection{X-Ray Diffraction Studies of Nanocomposites}

3.2.1. XRD of Pure PMMA and Its Composites: MS/PMMA (Where $M=Z n$ or $C d$ ). The XRD pattern of pure PMMA, $\mathrm{ZnS} / \mathrm{PMMA}$, and CdS/PMMA nanocomposites measured in the scan range of 10 to $80^{\circ}$ is shown in Figure 5(a). The amorphous nature of PMMA is indicated by the presence of the first broad peak at lower diffraction angle around $\left(10-20^{\circ}\right)$. From the pattern, the characteristic peak for pure PMMA is observed at $2 \theta$ value $=12.85^{\circ}$ [44]. $\mathrm{ZnS} / \mathrm{PMMA}$ exhibits two broadened diffraction peaks (from $25^{\circ}-43^{\circ}$ ) which may be due to overlapping of (100), (002), and (101) miller indices. These peaks correlate well with hexagonal $\mathrm{ZnS}$ wurtzite (structure standard pattern of JCPDS card number $80-0007)$. The diffraction peaks are in agreement with earlier reported studies [45, 46]. For the CdS/PMMA the diffraction peaks appeared at $13.32^{\circ}, 28.24^{\circ}, 43.13^{\circ}$, and $52.88^{\circ}$. The diffraction peaks at $2 \theta=13.32^{\circ}$ are the typical of PMMA. The peaks at $28.24^{\circ}, 43.13^{\circ}$, and $52.88^{\circ}$ are indexed to scattering from the (111), (220), and (311) cubic phase of CdS planes [47]. The mean crystallite sizes of the $\mathrm{ZnS} / \mathrm{PMMA}$ and CdS/PMMA could not be calculated using the Debye-Scherer equation due to the overlap of the nanoparticles and polymer peaks. The broadening of the XRD peaks is indicative of the small particle sizes of the as-prepared nanocomposites [48].

3.2.2. XRD of Pure PVA and Its Composites: MS/PVA (Where $M=Z n$ or $C d)$. XRD pattern of pure PVA, PVA/ZnS, and PVA/CdS is shown in Figure 5(b). The diffraction peaks of the pure PVA exhibits four peaks at $2 \theta=10.81^{\circ}, 19.37^{\circ}, 22.52^{\circ}$, and $40.19^{\circ}$ which correspond to the crystalline phase of PVA [49]. The crystalline nature of PVA stems up from the strong intermolecular interaction between PVA chains through the intermolecular hydrogen bonding [50]. In the diffraction pattern of the $\mathrm{ZnS} / \mathrm{PVA}$, the peaks that are attributable to $\mathrm{ZnS}$ nanoparticles of the composite are observed at $2 \theta=26.94^{\circ}$, $47.01^{\circ}$ and their miller indices are (100) and (110), which suggest the presence of hexagonal phase of $\mathrm{ZnS}$ (wurtzite). Similar results have been reported in literature [51]. $2 \theta=$ $19.37^{\circ}, 22.52^{\circ}, 40.19^{\circ}$, and $22.15^{\circ}$ being characteristic peak of PVA component. Nevertheless, another peak is expected around $2 \theta=52^{\circ}(103)$ and this is not distinguishable. This observation has been reported in previous research by other authors [52].

The low intensity of ZnS/PVA peaks can be attributed to interaction of metal sulfides with PVA; metal sulfides decrease the degree of PVA crystallinity when incorporated in PVA polymer [53]. In the XRD pattern of the PVA/CdS composite, the characteristic peak of the PVA is noticeable with other peaks at $2 \theta=10.96^{\circ}, 19.73^{\circ}, 22.50^{\circ}, 31.74^{\circ}$, and $40.72^{\circ}$ and their miller indices are (100), (101), (200), (002), and (111), respectively. The peaks from the CdS nanoparticles of the composites are observed at $2 \theta=26.57^{\circ}, 36.63^{\circ}, 46.26^{\circ}$, and $52.42^{\circ}$. These peaks could be indexed to the scattering from (111), (102), (103), and (311) hexagonal and cubic phase of CdS, respectively. The peaks correlate with both diffraction peaks associated with hexagonal phase of $\mathrm{CdS}(2 \theta=36.84$ and $46.82^{\circ}$ ) [54] and cubic phase of CdS (26.85 and 52.24 ${ }^{\circ}$ ) [55] and indicate the admixture of both phases. The particles sizes could not be calculated from using Debye-Scherer equation because the peaks overlap with the polymer peaks.

3.2.3. XRD of Pure PVP and Its Composites: MS/PVP (Where $M=Z n$ or $C d$ ). Figure $6(\mathrm{c})$ shows the XRD patterns of the pure PVP, and its respective nanocomposites are ZnS/PVP and CdS/PVP. The peaks around $2 \theta=10.5^{\circ}$ and $21.53^{\circ}$ are typical characteristic peak of PVP [56-59]. ZnS/PVP shows two peaks at $2 \theta=10.5^{\circ}$ and $21.53^{\circ}$, which correspond to the characteristic peak of pure PVP and another two broadened peaks which may be ascribed to the wurtzite phase of $\mathrm{ZnS}$. This diffraction pattern is in agreement with earlier observation [46]. The XRD pattern of the PVP/CdS exhibited 4 peaks at $2 \theta=25.39^{\circ}, 43.06^{\circ}, 46.82^{\circ}$, and $51.70^{\circ}$ which correspond to the (111), (220), and (311) miller indices. These peaks match with the cubic CdS of JCPDS file (JCPDS number 10-454) [60]. The absence of peaks at $2 \theta$ values of $24.8^{\circ}$, 


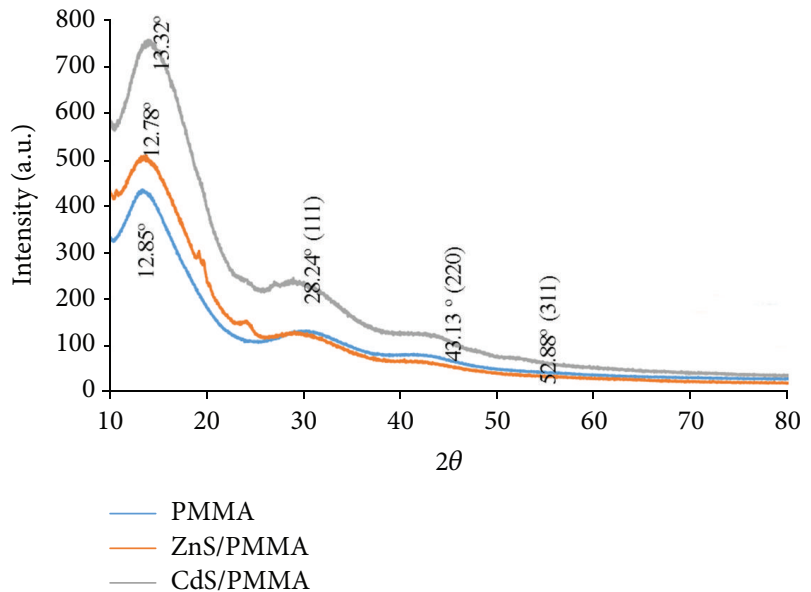

(a)

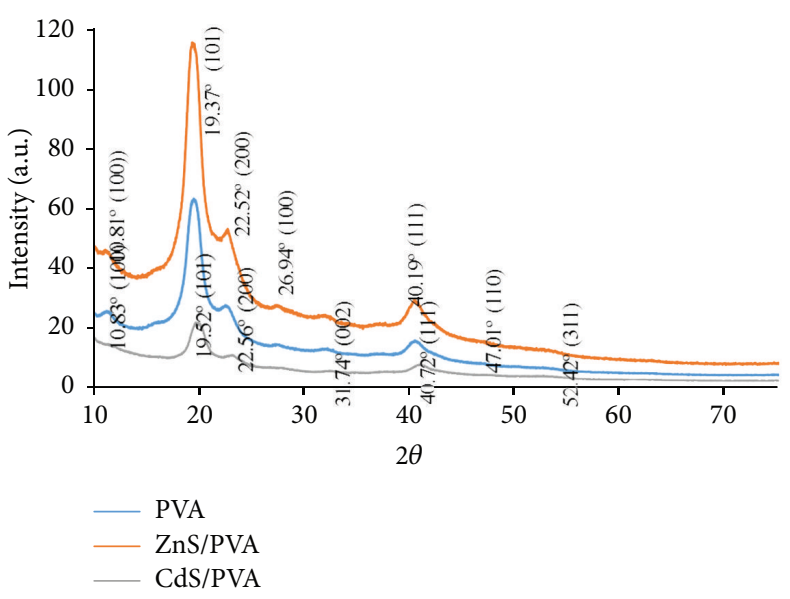

(b)

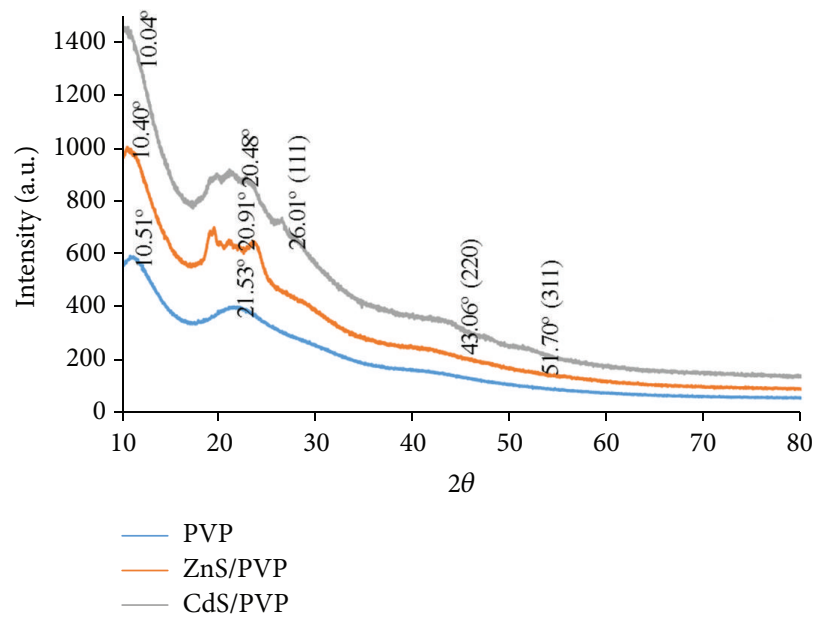

(c)

FIGURE 5: XRD diffractions patterns of pure PMMA and its respective nanocomposites (a), pure PVA and its respective nanocomposites (b), and pure PVP and its respective nanocomposites (c).

$36.2^{\circ}$, and $47.84^{\circ}$ ruled out the possibility of hexagonal phase $\mathrm{CdS}$ presence in CdS/PVP [61]. The average particle sizes of $\mathrm{ZnS} / \mathrm{PVP}$ and CdS/PVP could not be calculated using DebyeScherer formula due to the overlap of the nanoparticles and polymer peaks. Hence, they were estimated from TEM and UV-visible.

\subsection{Transmission Electron Microscopy (TEM) Studies.} Figure 6(a) shows the TEM images of the ZnS/PMMA, which appeared as slightly spherical shape, which are loosely distributed with an average particle size in the range of 1.51$3.35 \mathrm{~nm}$. Figure 6(b) shows the CdS/PMMA nanocomposites with $\mathrm{CdS}$ also embedded in the matrices of PMMA. The nanoparticles have a rod shape and with an average size in the range of 4.07-6.92 $\mathrm{nm}$. These particles are homogenous and almost equally distributed in the PMMA matrices. It could be noted that there occurs a slight difference in the particle size estimation using the XRD and the TEM and this can be ascribed to the intrinsic twining and dislocation present in the lattice of the sample [62]. Figures 6(c) and 6(d) represent the TEM micrograph of $\mathrm{ZnS} / \mathrm{PVA}$ and CdS/PVA, respectively. Figure 6(c) shows the incorporated $\mathrm{ZnS}$ nanoparticles in PVA matrices. The nanoparticles are rod-shaped with sizes in the range of $2.44-5.87 \mathrm{~nm}$. TEM micrograph in Figure 6(d) reveals cocoon-like shaped materials with size in the region of $2.57-4.90 \mathrm{~nm}$. The nanoparticles appear to be polydispersed and aggregated.

The TEM micrograph of ZnS/PVP presented in Figure 6(e) reveals uniform distribution of spherical $\mathrm{ZnS}$ embedded in the polymer matrices of the PVP. The sizes of the $\mathrm{ZnS}$ nanoparticles are in the range of $1.5-3.25 \mathrm{~nm}$. It is apparent from the TEM micrograph of CdS/PVP, Figure 6(f), that $\mathrm{CdS}$ nanoparticles embedded in the polymer matrix of PVP are distinguishable, although they are in contact 

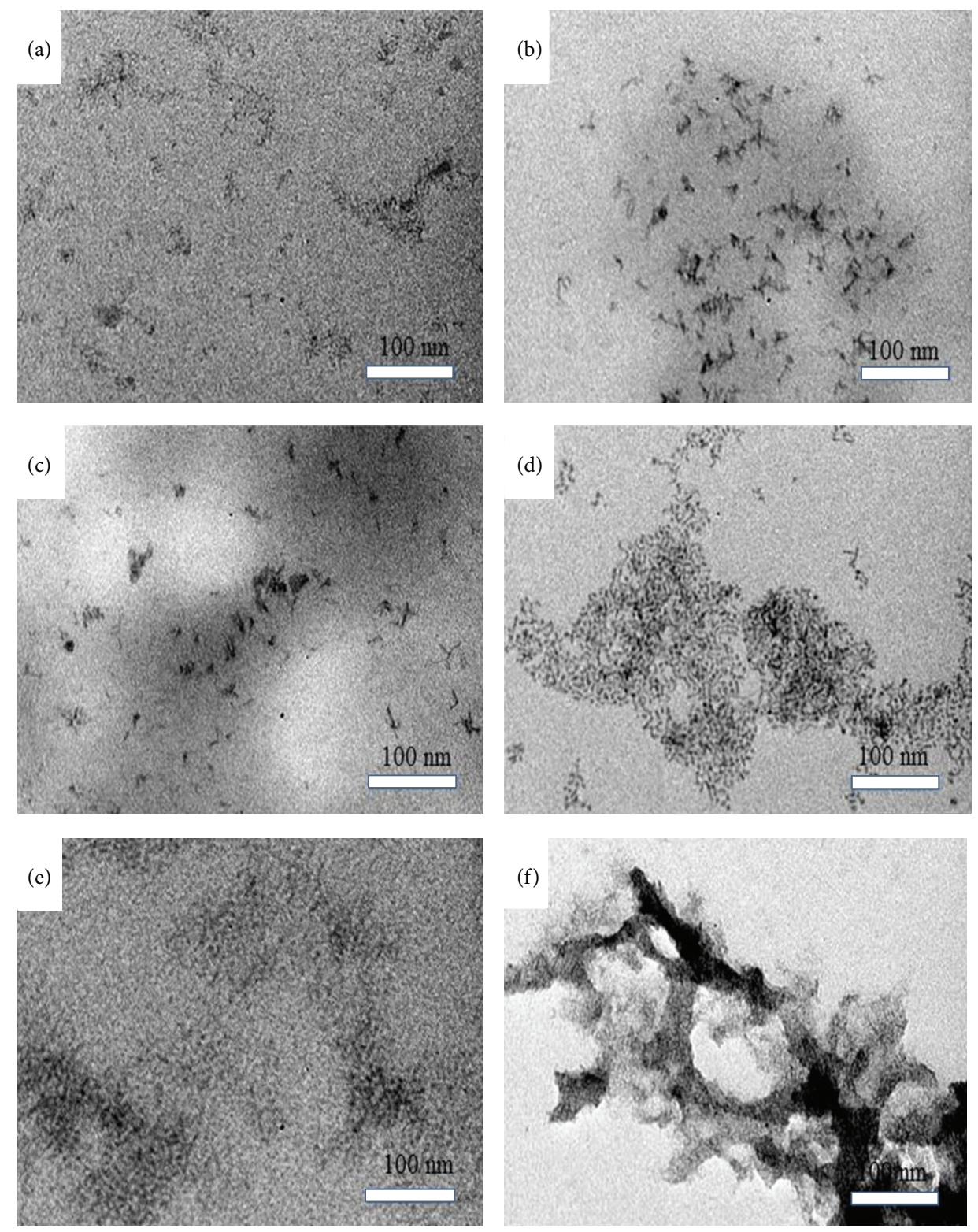

Figure 6: TEM micrographs of (a) ZnS/PMMA, (b) CdS/PMMA, (c) ZnS/PVA, (d) CdS/PVA, (e) ZnS/PVP, and (f) CdS/PVP.

with one another. They are bit agglomerated into a massive structure although they reveal an average particle size whose range is in the region of $1.75-4.55 \mathrm{~nm}$.

3.4. Scanning Electron Microscopy of (SEM) Studies. The micrographs shown in Figures 7(a)-7(e) are a representative SEM image of the pure PMMA, the PMMA/ZnS, and PMMA/CdS at low and high magnifications and it was observed that the $\mathrm{ZnS}$ nanofillers cause remarkable change in the morphology of pure PMMA (as observed in Figure 7(b)). Higher magnification images show the presence of slight agglomeration, and this might be due to the existence of a larger interaction between nanoparticles as compared with polymer-particle interaction [63]. The SEM image of the PMMA/CdS presented in Figure 7(d) exhibited homogenous dispersion of $\mathrm{CdS}$ in the PMMA unlike the agglomeration observed at higher magnification, Figure $7(\mathrm{e})$.

The micrograph in Figures 8(a)-8(e) shows the pure PVA, ZnS/PVA, and CdS/PVA nanocomposites. The pure PVA is made up of fine spherical material. There is a significant change in the morphology of PVA/ZnS and CdS/PVA with the former exhibiting a uniform dispersion of the ZnS nanofillers in the PVA polymer matrices, Figure 8(b). The SEM micrograph of PVA/CdS at higher magnification displays an almost splitting image of the pure PVA with CdS embedded in the polymeric matrix. The image shows rounded spheres of uniformly dispersed CdS nanoparticles in the PVA polymer matrix. Pure PVP is presented in 

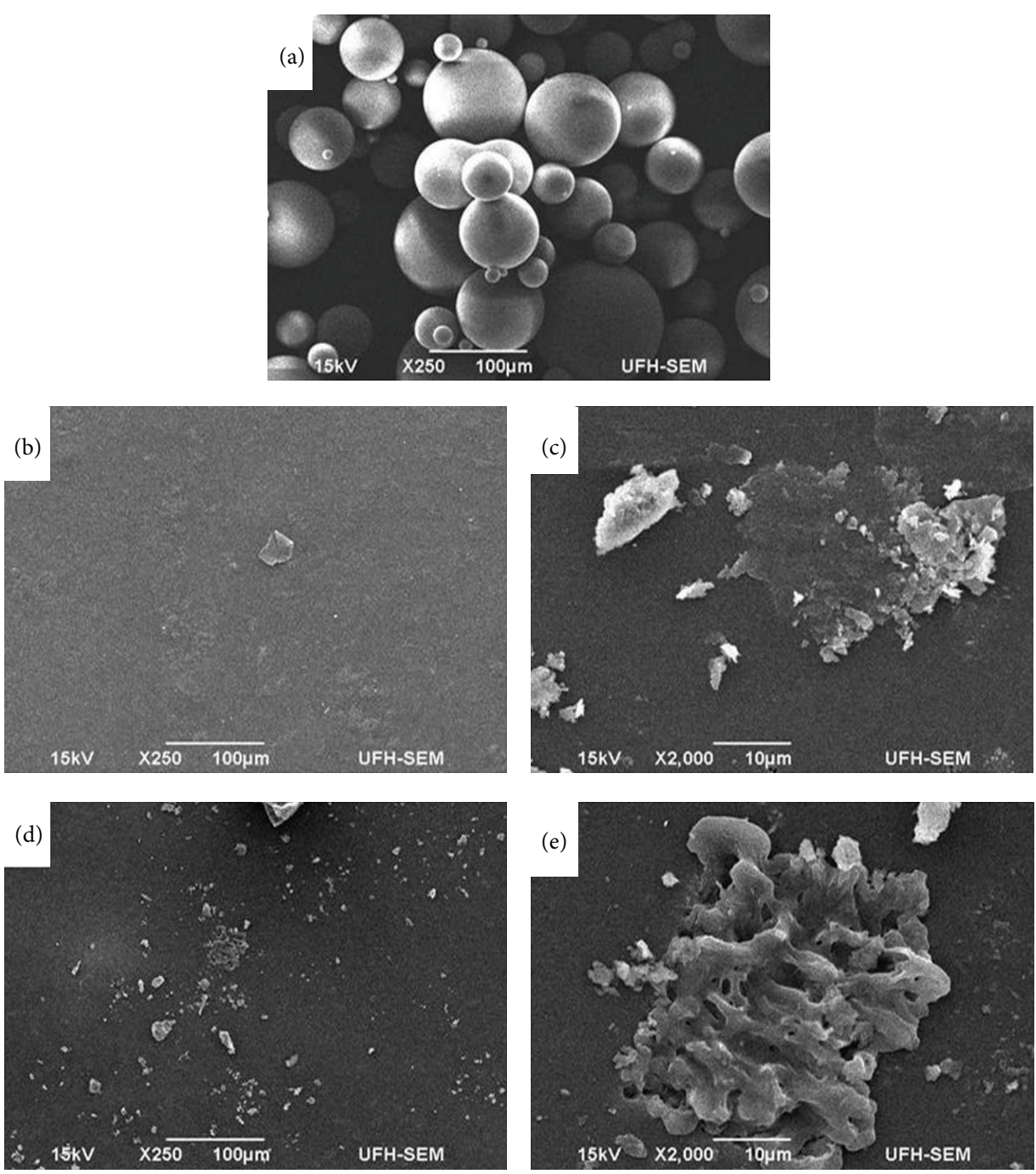

FIguRe 7: SEM micrographs of (a) pure PMMA, (b) ZnS/PMMA-low mag., (c) ZnS/PMMA-high mag., (d) CdS/PMMA-low mag., and (e) CdS/PMMA-high magnification.

Figure 9(a), with a smooth flower-like material. Part of the ZnS/PVP layers appeared to be exfoliated with the $\mathrm{ZnS}$ embedded in the PVP polymer matrix, Figures 9(b) and $9(\mathrm{c})$. The micrograph of CdS/PVP at lower magnification, Figure 9(d), did not show an appreciable result unlike the image at higher magnification which shows the CdS that appeared to be incorporated in the matrix of the PVP as spherical uniformly dispersed particles, Figure 9(e).

3.5. Optical Property of the Nanocomposites. The absorptions spectra of the pure polymers with the respective nanocomposites are presented in Figures 10(a)-10(c). All the polymers are not absorbed within the measured range as evident in the absence of absorption peak in the spectrum. The onset absorption for CdS/PMMA, CdS/PVA, and CdS/PVP was found as a shoulder at approximately $457 \mathrm{~nm}(2.72 \mathrm{eV}), 441 \mathrm{~nm}(2.82 \mathrm{eV})$, and $438 \mathrm{~nm}(3.21 \mathrm{eV})$, respectively. The absorption peak of these nanocomposites shows that they are $58 \mathrm{~nm}, 74 \mathrm{~nm}$, and $77 \mathrm{~nm}$ blue shifted from the bulk CdS, $515 \mathrm{~nm}(2.40 \mathrm{eV})$ [64]. The spectra of the ZnS/PMMA, ZnS/PVA, and ZnS/PVP show absorption on set at approximately $316 \mathrm{~nm}(3.92 \mathrm{eV}), 314 \mathrm{~nm}(2.25 \mathrm{eV})$, and $327 \mathrm{~nm}(3.42 \mathrm{eV})$, respectively. When compared with the bulk ZnS $340 \mathrm{~nm}(3.66 \mathrm{eV})$ [65], they are $24 \mathrm{~nm}, 26 \mathrm{~nm}$, and $13 \mathrm{~nm}$ blue shifted. The blue shifts of the polymer nanocomposites are indicative of quantum confinements of the embedded nanoparticles. It is important to note that all the nanocomposites exhibit enhanced quantum confinement except CdS/PMMA and CdS/PVA when compared with the HDA-capped ZnS and CdS that were earlier reported [23]. The optical band gap energy of nanocrystalline samples is 

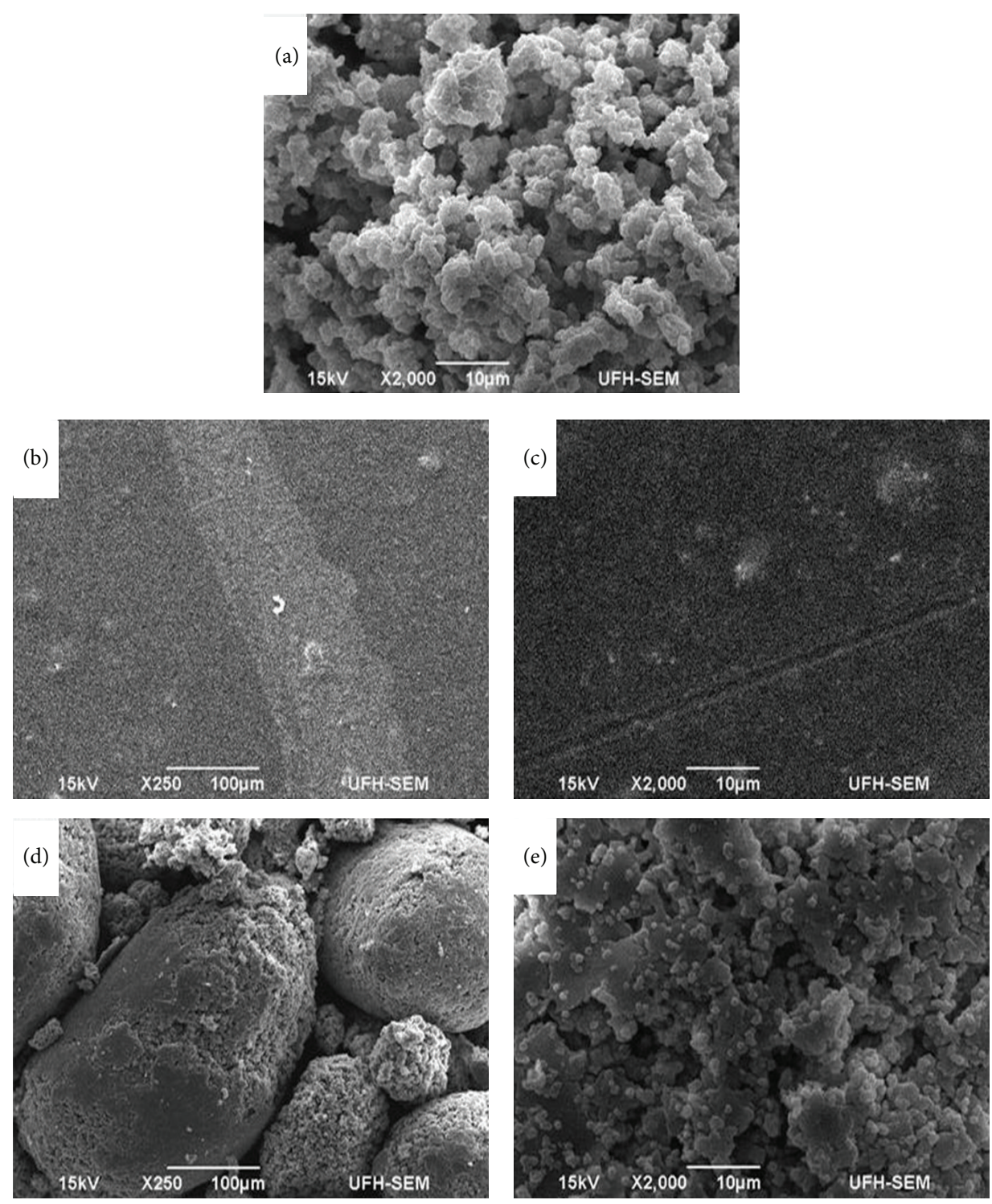

FIGURE 8: SEM micrographs of (a) pure PVA, (b) ZnS/PVA-low mag., (c) ZnS/PVA-high mag., (d) CdS/PVA-low mag., and (e) CdS/PVA-high mag.

determined from the absorption on-set of the various UVVis spectra and it can be calculated from the absorption peak [66].

UV-Vis spectrum is used to calculate the particle size of nanocrystals using the effective mass approximation formula (EMA) [67]:

$$
E_{\mathrm{np}}=E_{g}+\frac{h \pi^{2}}{2 R^{2}}\left[\frac{1}{m_{e}}+\frac{1}{m_{h}}\right]-\frac{18 e^{2}}{4 \pi \varepsilon_{0} \varepsilon_{r} R},
$$

where $E_{\text {np }}$ is the band gap of the nanoparticle, $E_{g}$ is the band gap of the bulk $\mathrm{ZnS}$ or CdS, $m_{e}$ is the effective mass of electron (0.4), $m_{h}$ is the effective mass of hole (0.61) for $\mathrm{ZnS}, m_{e}=(0.19)$, and $m_{h}=(0.8)$ for CdS. $R$ is the radius of the particle, $\varepsilon_{0}$ is the permittivity of free space, and $\varepsilon_{r}$ is the dielectric constant. The dielectric constants of $\mathrm{ZnS}$ and $\mathrm{CdS}$ are 5.2 and 5.7, respectively. Table 2 shows the summary of the optical properties of the various polymer nanocomposite.

\section{Conclusion}

In this work, $\mathrm{ZnS}$ and $\mathrm{CdS}$ were incorporated into PMMA, PVA, and PVP matrices to form corresponding metal sulfides/polymer nanocomposites. The structural and thermal properties of the composites were studied with XRD, TEM, SEM, and TGA. Wurtzite crystalline phase of ZnS was obtained from the XRD analysis for all the $\mathrm{ZnS}$ polymer nanocomposites. Cubic phase of CdS was also displayed by the CdS/PMMA and CdS/PVP but the CdS/PVA showed the combination of both cubic and hexagonal phase of $\mathrm{CdS}$ in PVA composite. TEM micrograph shows that the sizes 
TABLE 2: Optical band gaps and blue shifts of absorption band of the metal sulfides/polymer nanocomposites.

\begin{tabular}{lccc}
\hline Sample & Wavelength $(\mathrm{nm})$ & Band gap $(\mathrm{eV})$ & Blue shift $(\mathrm{eV})$ \\
\hline ZnS/PMMA & 316 & 3.92 & 0.26 \\
CdS/PMMA & 457 & 2.71 & 0.31 \\
ZnS/PVA & 314 & 3.95 & 0.29 \\
CdS/PVA & 441 & 2.82 & 0.42 \\
ZnS/PVP & 327 & 3.79 & 0.13 \\
CdS/PVP & 438 & 2.83 & 0.43 \\
\hline
\end{tabular}
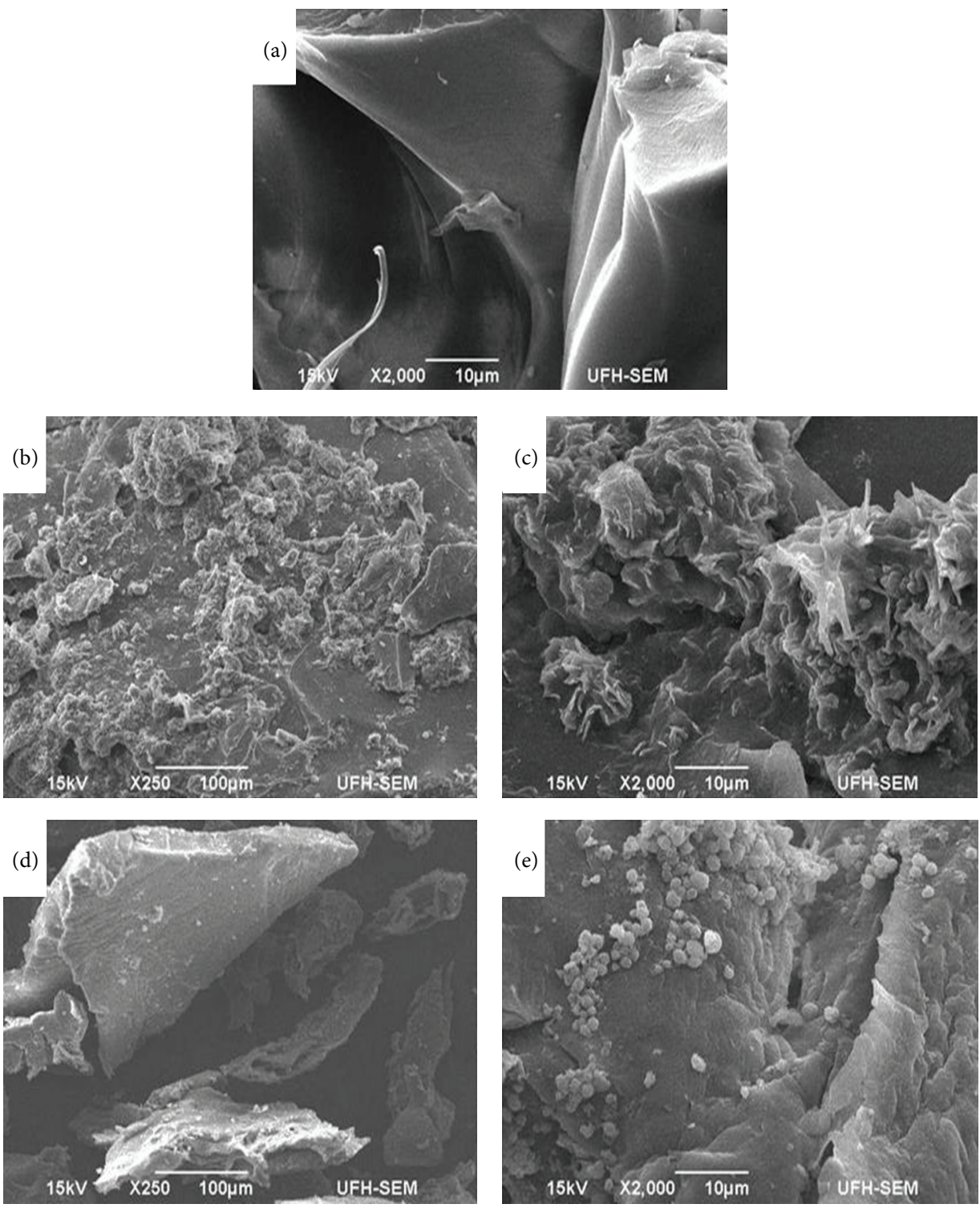

FigURE 9: SEM micrographs of (a) pure PVP, (b) ZnS/PVP-low mag., (c) ZnS/PVP-high mag., (d) CdS/PVP-low mag., and (e) CdS/PVP-high mag.

of the metal sulfides in the composites are in the range of $1.59-6.9 \mathrm{~nm}$ and these values are in close agreement with the ones obtained from the XRD. SEM micrographs show almost uniform dispersion of the $\mathrm{ZnS}$ and $\mathrm{CdS}$ nanoparticles in the respective polymers. The TGA reveals that the ZnS/PVA and CdS/PVA thermal stability are most enhanced by the incorporation of the metal sulfide in the matrices of the polymers. All except CdS/PMMA and CdS/PVA show greater degree of quantum confinement when metal sulfide was incorporated into the various polymer matrices which are 


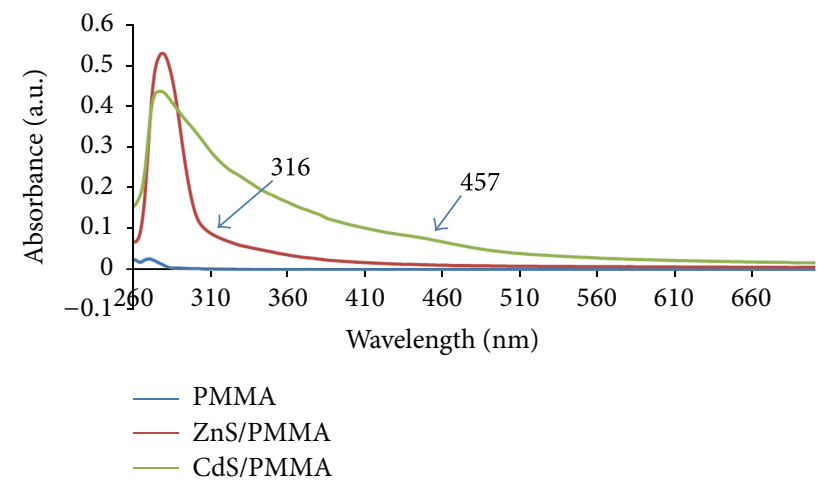

(a)

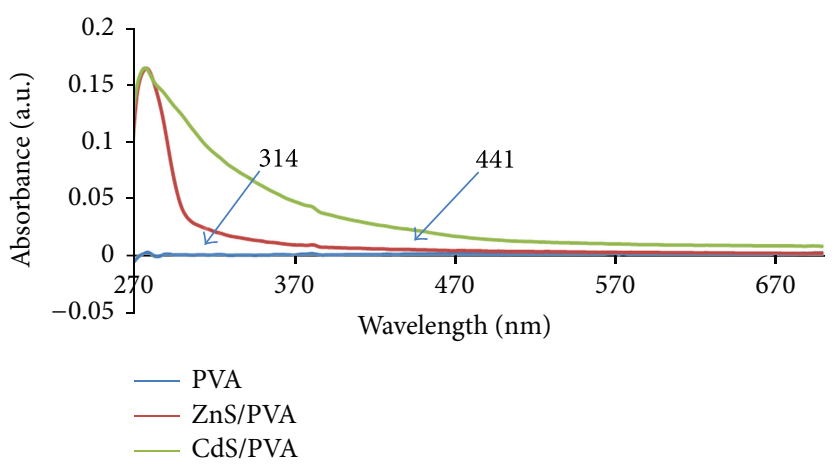

(b)

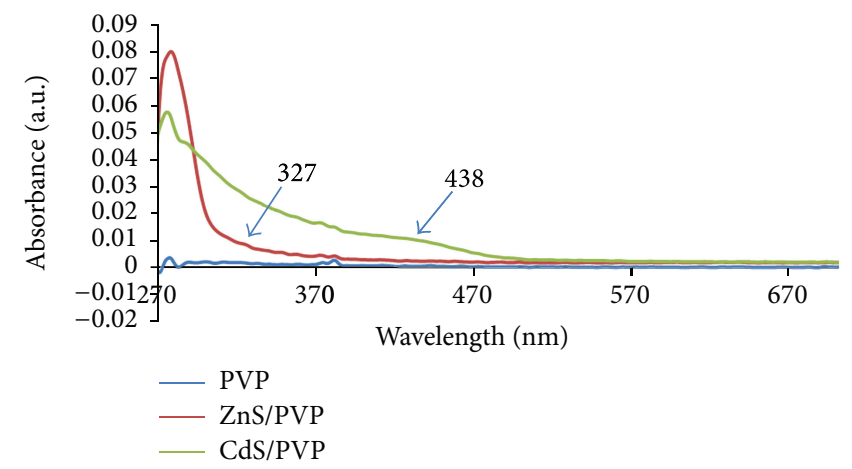

(c)

FIGURE 10: Absorption spectra of (a) PMMA, ZnS/PMMA, and CdS/PMMA, (b) PVA ZnS/PVA, and CdS/PVA, and (c) PVP, ZnS/PVP, and $\mathrm{PVP} / \mathrm{CdS}$.

compared with the HDA-capped ZnS and CdS nanoparticles previously reported.

\section{Conflict of Interests}

The authors declare that there is no conflict of interests regarding the publication of this paper.

\section{Acknowledgment}

The authors greatly recognize the considerable support from Govan Mbeki Research and Development Centre (GMRDC), University of Fort Hare, South Africa.

\section{References}

[1] T. E. Twardowski, Introduction to Nanocomposites Material Properties, Processing, Characterization, Destech Publications, Lancaster, Pa, USA, 2007.

[2] M. Tamborra, M. Striccoli, R. Comparelli, M. L. Curri, A. Petrella, and A. Agostiano, "Optical properties of hybrid composites based on highly luminescent CdS nanocrystals in polymer," Nanotechnology, vol. 15, no. 4, pp. S240-S244, 2004.

[3] F. Hussain, M. Hojjati, M. Okamoto, and R. E. Gorga, "Polymermatrix nanocomposites, processing, manufacturing, and application: an overview," Journal of Composite Materials, vol. 40, no. 17, pp. 1511-1575, 2006.
[4] V. Resta, A. M. Laera, A. Camposeo et al., "Spatially confined CdS NCs in situ synthesis through laser irradiation of suitable unimolecular precursor-doped polymer," Journal of Physical Chemistry C, vol. 116, no. 47, pp. 25119-25125, 2012.

[5] H. Althues, R. Palkovits, A. Rumplecker et al., "Synthesis and characterization of transparent luminescent $\mathrm{ZnS}: \mathrm{Mn} / \mathrm{PMMA}$ nanocomposites," Chemistry of Materials, vol. 18, no. 4, pp. 1068-1072, 2006.

[6] C. Wang, L. Guan, Y. Mao et al., "Optical nonlinearity of ZnSpolyvinyl pyrrolidone nanocomposite suspension," Journal of Physics D: Applied Physics, vol. 42, no. 4, Article ID 045403, 2009.

[7] J. P. Borah and K. C. Sarma, "Photo-physical properties of of ZnS/PVA nanocrystals," Optoelectronics and Advanced Materials, Rapid Communications, vol. 3, no. 9, pp. 891-898, 2009.

[8] N. Soltani, E. Saion, W. M. M. Yunus et al., "Photocatalytic degradation of methylene blue under visible light using PVPcapped ZnS and CdS nanoparticles," Solar Energy, vol. 97, pp. 147-154, 2013.

[9] S. W. Shin, S. Ra Kang, J. Ho Yun et al., "Effect of different annealing conditions on the properties of chemically deposited $\mathrm{ZnS}$ thin films on ITO coated glass substrates," Solar Energy Materials and Solar Cells, vol. 95, no. 3, pp. 856-863, 2011.

[10] E. K. Goharshadi, R. Mehrkhah, and P. Nancarrow, "Synthesis, characterization, and measurement of structural, optical, and phtotoluminescent properties of zinc sulfide quantum dots," Materials Science in Semiconductor Processing, vol. 16, no. 2, pp. 356-362, 2013. 
[11] B. Su and K. L. Choy, "Microstructure and properties of the CdS thin films prepared by electrostatic spray assisted vapour deposition (ESAVD) method," Thin Solid Films, vol. 359, no. 2, pp. 160-164, 2000.

[12] Y. Kashiwaba, J. Sato, and T. Abe, "Emission of lights of various colors from p-CdS:Cu/n-CdS thin-film diodes," Applied Surface Science, vol. 212-213, pp. 162-165, 2003.

[13] B.-T. Liu, P.-S. Li, W.-C. Chen, and Y.-Y. Yu, "Ex situ synthesis of high-refractive-index polyimide hybrid films containing $\mathrm{TiO}_{2}$ chelated by 4 -aminobenzoic acid," European Polymer Journal, vol. 50, no. 1, pp. 54-60, 2014.

[14] M. Montazer and M. Maali Amiri, " $\mathrm{ZnO}$ nano reactor on textiles and polymers: ex situ and in situ synthesis, application, and characterization," Journal of Physical Chemistry B, vol. 118, no. 6, pp. 1453-1470, 2014.

[15] M. Pentimalli, F. Antolini, E. M. Bauer, D. Capitani, T. Di Luccio, and S. Viel, "A solid state nuclear magnetic resonance study on the thermolytic synthesis of CdS nanoparticles in a polystyrene matrix," Materials Letters, vol. 60, no. 21-22, pp. 2657-2661, 2006.

[16] T. Di Luccio, A. M. Laera, L. Tapfer, S. Kempter, R. Kraus, and B. Nickel, "Controlled nucleation and growth of CdS nanoparticles in a polymer matrix," Journal of Physical Chemistry B, vol. 110, no. 25, pp. 12603-12609, 2006.

[17] W. J. Danaher, L. E. Lyons, and G. C. Morris, "Some properties of thin films of chemically deposited cadmium sulphide," Solar Energy Materials, vol. 12, no. 2, pp. 137-148, 1985.

[18] L. Y. Ding, T. Li, Y. M. Zhong, C. Fan, and J. Huang, "Synthesis and characterization of a novel nitric oxide fluorescent probe CdS-PMMA nanocomposite via in-situ bulk polymerization," Materials Science and Engineering C, vol. 35, no. 1, pp. 29-35, 2014.

[19] L. Pedone, E. Caponetti, M. Leone et al., "Synthesis and characterization of CdS nanoparticles embedded in a poly(methyl methacrylate) matrix," Journal of Colloid and Interface Science, vol. 284, no. 2, pp. 495-500, 2005.

[20] P. K. Khanna, R. R. Gokhale, V. V. V. S. Subbarao, N. Singh, K.-W. Jun, and B. K. Das, "Synthesis and optical properties of CdS/PVA nanocomposites," Materials Chemistry and Physics, vol. 94, no. 2-3, pp. 454-459, 2005.

[21] M. Pattabi, B. Saraswathi Amma, and K. Manzoor, "Photoluminescence study of PVP capped CdS nanoparticles embedded in PVA matrix," Materials Research Bulletin, vol. 42, no. 5, pp. 828835, 2007.

[22] A. M. Abdelghany, E. M. Abdelrazek, and D. S. Rashad, "Impact of in situ preparation of CdS filled PVP nano-composite," Spectrochimica Acta Part A: Molecular and Biomolecular Spectroscopy, vol. 130, pp. 302-308, 2014.

[23] P. A. Ajibade and J. Osuntokun, "Synthesis and characterization of hexadecylamine capped $\mathrm{ZnS}$, CdS, and $\mathrm{HgS}$ nanoparticles using heteroleptic single molecular precursors," Journal of Nanomaterials, vol. 2014, Article ID 782526, 7 pages, 2014.

[24] A. Abdelghany, M. Mekhail, E. Abdelrazek, and M. Aboud, "Combined DFT/FTIR structural studies of monodispersed PVP/Gold and silver nano particles," Journal of Alloys and Compounds, vol. 646, pp. 326-332, 2015.

[25] V. Mathur and K. Sharma, "Evaluation of morphological effect on thermal and mechanical performance of PS/PMMA/CdS nanocomposite," Advances in Nanoparticles, vol. 2, no. 3, pp. 205-216, 2013.

[26] A. K. Thottoli and A. K. Achuthanunni, "Effect of polyvinyl alcohol concentration on the $\mathrm{ZnS}$ nanoparticles and wet chemical synthesis of wurtzite ZnS nanoparticles," Journal of Nanostructure in Chemistry, vol. 3, no. 1, article 31, 2013.

[27] A. M. Shehap, "Thermal and spectroscopic studies of polyvinyl alcohol/sodium carboxymethyl cellulose blends," Egyptian Journal of Solids, vol. 31, no. 1, pp. 75-91, 2008.

[28] C. H. L. Raju, J. L. Rao, B. C. V. Reddy, and K. V. Brahmam, "Thermal and IR studies on copper doped polyvinyl alcohol," Bulletin of Materials Science, vol. 30, no. 3, pp. 215-218, 2007.

[29] P. B. Khoza, M. J. Moloto, and L. M. Sikhwivhilu, "The effect of solvents, acetone, water, and ethanol, on the morphological and optical properties of $\mathrm{ZnO}$ nanoparticles prepared by microwave," Journal of Nanotechnology, vol. 2012, Article ID 195106, 6 pages, 2012.

[30] J. Osuntokun and P. A. Ajibade, "Synthesis and structural characterization of CdS nanoparticles using nitrogen adducts of mixed diisopropylthiourea and dithiolate derivatives of $\mathrm{Cd}(\mathrm{II})$ complexes," Superlattices and Microstructures, vol. 83, pp. 89100, 2015.

[31] K. E. Strawhecker and E. Manias, "AFM of poly(vinyl alcohol) crystals next to an inorganic surface," Macromolecules, vol. 34, no. 24, pp. 8475-8482, 2001.

[32] K. E. Strawhecker and E. Manias, "Structure and properties of poly(vinyl alcohol)/ $\mathrm{Na}^{+}$montmorillonite nanocomposites," Chemistry of Materials, vol. 12, no. 10, pp. 2943-2949, 2000.

[33] S. Ummartyotin, N. Bunnak, J. Juntaro, M. Sain, and H. Manuspiya, "Hybrid organic-inorganic of $\mathrm{ZnS}$ embedded PVP nanocomposite film for photoluminescent application," Comptes Rendus Physique, vol. 13, no. 9-10, pp. 994-1000, 2012.

[34] A. M. Abdelghany, E. M. Abdelrazek, and D. S. Rashad, "Impact of in situ preparation of CdS filled PVP nano-composite," Spectrochimica Acta-Part A: Molecular and Biomolecular Spectroscopy, vol. 130, pp. 302-308, 2014.

[35] V. Gianotti, D. Antonioli, K. Sparnacci et al., "On the thermal stability of PS-b-PMMA block and P(S-r-MMA) random copolymers for nanopatterning applications," Macromolecules, vol. 46, no. 20, pp. 8224-8234, 2013.

[36] A. K. Kole, S. Gupta, P. Kumbhakar, and P. C. Ramamurthy, "Nonlinear optical second harmonic generation in $\mathrm{ZnS}$ quantum dots and observation on optical properties of $\mathrm{ZnS} / \mathrm{PMMA}$ nanocomposites," Optics Communications, vol. 313, pp. 231-237, 2014.

[37] Y.-L. Liu, C.-Y. Hsu, and K.-Y. Hsu, "Poly(methyl methacrylate)-silica nanocomposites films from surface-functionalized silica nanoparticles," Polymer, vol. 46, no. 6, pp. 1851-1856, 2005.

[38] X. Gong, C. Y. Tang, L. Pan, Z. Hao, and C. P. Tsui, “Characterization of poly(vinyl alcohol) (PVA)/ZnO nanocomposites prepared by a one-pot method," Composites Part B: Engineering, vol. 60, pp. 144-149, 2014.

[39] J. Wang, C. Gao, Y. Zhang, and Y. Wan, "Preparation and in vitro characterization of BC/PVA hydrogel composite for its potential use as artificial cornea biomaterial," Materials Science and Engineering C, vol. 30, no. 1, pp. 214-218, 2010.

[40] J. George, K. V. Ramana, A. S. Bawa, and Siddaramaiah, "Bacterial cellulose nanocrystals exhibiting high thermal stability and their polymer nanocomposites," International Journal of Biological Macromolecules, vol. 48, no. 1, pp. 50-57, 2011.

[41] M. R. Kumar and G. Murugadoss, "Synthesis and study of optical and thermal properties of Mn doped CdS nanoparticles using polyvinylpyrrolidone," Journal of Luminescence, vol. 146, pp. 325-332, 2014. 
[42] Y. K. Du, P. Yang, Z. G. Mou, N. P. Hua, and L. Jiang, "Thermal decomposition behaviors of PVP coated on platinum nanoparticles," Journal of Applied Polymer Science, vol. 99, no. 1, pp. 23-26, 2006.

[43] N. M. Al-Hada, E. B. Saion, A. H. Shaari et al., "A facile thermal-treatment route to synthesize the semiconductor $\mathrm{CdO}$ nanoparticles and effect of calcination," Materials Science in Semiconductor Processing, vol. 26, no. 1, pp. 460-466, 2014.

[44] S. Agrawal, D. Patidar, and N. S. Saxena, "Glass transition temperature and thermal stability of ZnS/PMMA nanocomposites," Phase Transitions, vol. 84, no. 11-12, pp. 888-900, 2011.

[45] H. Zhang and L. Qi, "Low-temperature, template-free synthesis of wurtzite $\mathrm{ZnS}$ nanostructures with hierarchical architectures," Nanotechnology, vol. 17, no. 15, pp. 3984-3988, 2006.

[46] S. Kumar and S. K. Sharma, "Growth and characterization of large-scale uniform Zinc Sulfide nanowires by a simple chemical reaction technique," Superlattices and Microstructures, vol. 46, no. 4, pp. 687-692, 2009.

[47] L. Ding, T. Li, Y. Zhong, C. Fan, and J. Huang, "Synthesis and characterization of a novel nitric oxide fluorescent probe CdS-PMMA nanocomposite via in-situ bulk polymerization," Materials Science and Engineering C, vol. 35, no. 1, pp. 29-35, 2014.

[48] R. Seoudi, A. A. Shabaka, M. Kamal, E. M. Abdelrazek, and W. Eisa, "Dependence of spectroscopic and electrical properties on the size of cadmium sulfide nanoparticles," Physica E, vol. 45, pp. 47-55, 2012.

[49] A. K. Shahi, B. K. Pandey, S. C. Singh, and R. Gopal, "Observation of negative persistent photoconductivity in ZnS/PVA nanocomposite materials," Journal of Alloys and Compounds, vol. 588, pp. 440-448, 2014.

[50] D. Saikia, P. K. Saikia, P. K. Gogoi, M. R. Das, P. Sengupta, and M. V. Shelke, "Synthesis and characterization of CdS/PVA nanocomposite thin films from a complexing agent free system," Materials Chemistry and Physics, vol. 131, no. 1-2, pp. 223-229, 2011.

[51] B. A. Prakasam, M. Lahtinen, A. Peuronen et al., "Phase selective synthesis of $\mathrm{ZnS}$ nanoparticles from structurally new dithiocarbamate precursor," Materials Letters, vol. 144, pp. 1921, 2015 .

[52] S. Liu, H. Zhang, and M. T. Swihart, "Spray pyrolysis synthesis of ZnS nanoparticles from a single-source precursor," Nanotechnology, vol. 20, no. 23, Article ID 235603, 2009.

[53] X. F. Qian, J. Yin, X. X. Guo, Y. F. Yang, Z. K. Zhu, and J. F. Lu, "Polymer-inorganic nanocomposites prepared by hydrothermal method: PVA/ZnS, PVA/CdS, preparation and characterization," Journal of Materials Science Letters, vol. 19, no. 24, pp. 2235-2237, 2000.

[54] N. Soltani, E. Saion, W. M. M. Yunus et al., "Enhancement of visible light photocatalytic activity of $\mathrm{ZnS}$ and $\mathrm{CdS}$ nanoparticles based on organic and inorganic coating," Applied Surface Science, vol. 290, pp. 440-447, 2014.

[55] P. Rodríguez-Fragoso, G. González de la Cruz, S. A. Tomás, J. G. Mendoza-Alvarez, and O. Zelaya Angel, "Photoluminescence of CdS nanoparticles embedded in a starch matrix," Journal of Luminescence, vol. 130, no. 7, pp. 1128-1133, 2010.

[56] X.-G. Li, I. Kresse, J. Springer, J. Nissen, and Y.-L. Yang, "Morphology and gas permselectivity of blend membranes of polyvinylpyridine with ethylcellulose," Polymer, vol. 42, no. 16, pp. 6859-6869, 2001.
[57] C. Liu, C. Xiao, and H. Liang, "Properties and structure of PVPlignin 'blend films," Journal of Applied Polymer Science, vol. 95, no. 6, pp. 1405-1411, 2005.

[58] J. Bai, Y. Li, M. Li et al., "A novel approach to prepare $\mathrm{AgCl} / \mathrm{PVP}$ nanocomposite microspheres via electrospinning with sol-gel method," Colloids and Surfaces A: Physicochemical and Engineering Aspects, vol. 318, no. 1-3, pp. 259-262, 2008.

[59] X.-F. Qian, J. Yin, S. Feng, S.-H. Liu, and Z.-K. Zhu, "Preparation and characterization of polyvinylpyrrolidone films containing silver sulfide nanoparticles," Journal of Materials Chemistry, vol. 11, no. 10, pp. 2504-2506, 2001.

[60] S. Muruganandam, G. Anbalagan, and G. Murugadoss, "Synthesis and structural, optical and thermal properties of CdS: $\mathrm{Zn}^{2+}$ nanoparticles," Applied Nanoscience, vol. 4, no. 8, pp. 1013-1019, 2014.

[61] P. Rodriguez, N. Muñoz-Aguirre, E. San-Martín Martinez, G. González de la Cruz, S. A. Tomas, and O. Zelaya Angel, "Synthesis and spectral properties of starch capped CdS nanoparticles in aqueous solution," Journal of Crystal Growth, vol. 310, no. 1, pp. 160-164, 2008.

[62] J. Nanda, S. Sapra, D. D. Sarma, N. Chandrasekharan, and G. Hodes, "Size-selected zinc sulfide nanocrystallites: synthesis, structure, and optical studies," Chemistry of Materials, vol. 12, no. 4, pp. 1018-1024, 2000.

[63] S. Agarwal, D. Patidar, and N. S. Saxena, "Effect of ZnS nanofiller and temperature on mechanical properties of poly(methyl methacrylate)," Journal of Applied Polymer Science, vol. 123, no. 4, pp. 2431-2438, 2012.

[64] H. Wang, Z. Chen, P. Fang, and S. Wang, "Synthesis, characterization and optical properties of hybridized CdS-PVA nanocomposites," Materials Chemistry and Physics, vol. 106, no. 2-3, pp. 443-446, 2007.

[65] L. Guo, S. Chen, and L. Chen, "Controllable synthesis of ZnS/PMMA nanocomposite hybrids generated from functionalized ZnS quantum dots nanocrystals," Colloid and Polymer Science, vol. 285, no. 14, pp. 1593-1600, 2007.

[66] S. Chowdhury, G. A. Ahmed, D. Mohanta, S. K. Dolui, D. K. Avasthi, and A. Choudhury, "Luminescence study of bare and coated CdS quantum dots: Effect of SHI irradiation and ageing," Nuclear Instruments and Methods in Physics Research, Section B: Beam Interactions with Materials and Atoms, vol. 240, no. 3, pp. 690-696, 2005.

[67] L. Brus, "Electronic wave functions in semiconductor clusters: experiment and theory," Journal of Physical Chemistry, vol. 90, no. 12, pp. 2555-2560, 1986. 

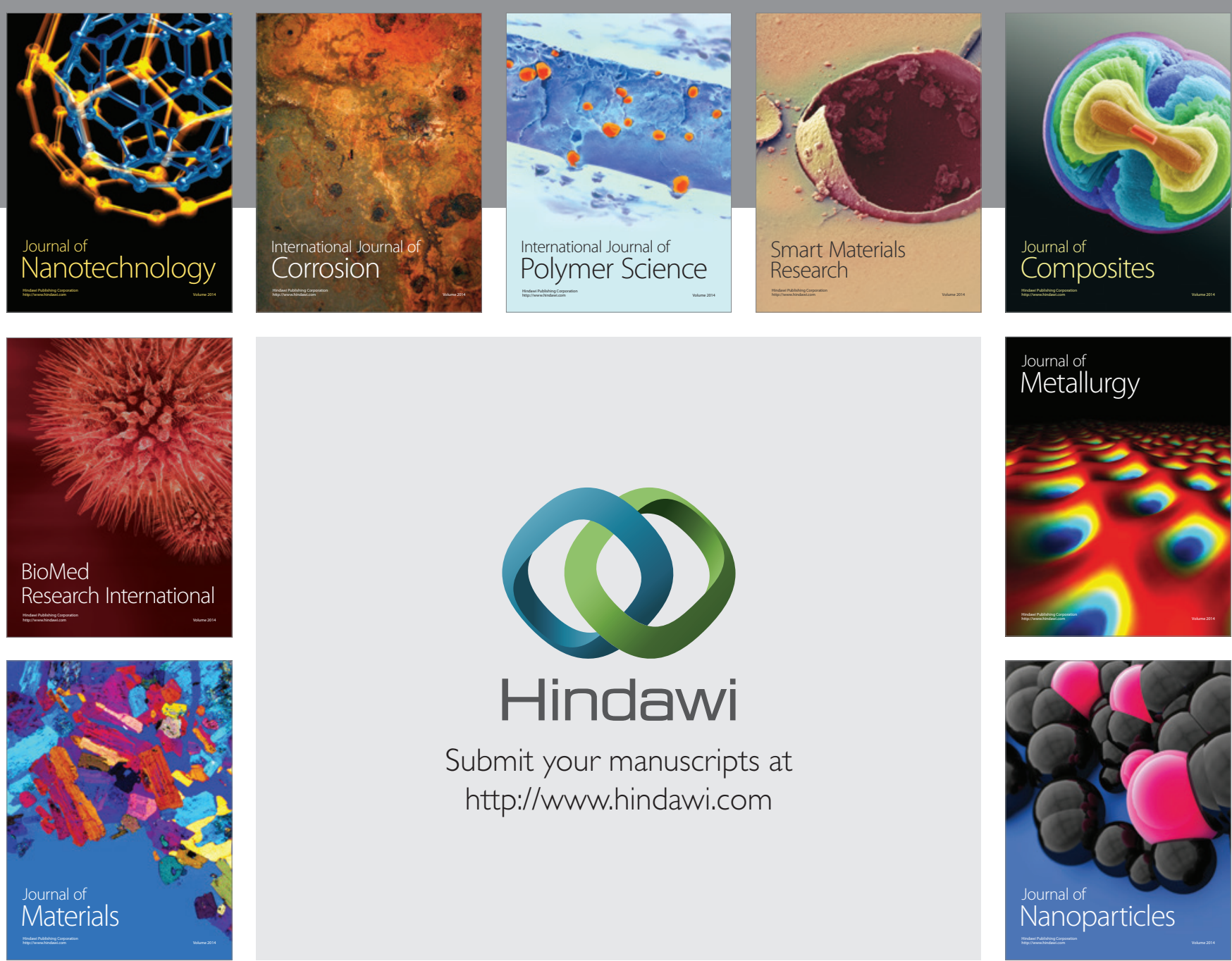

\section{Hindawi}

Submit your manuscripts at

http://www.hindawi.com

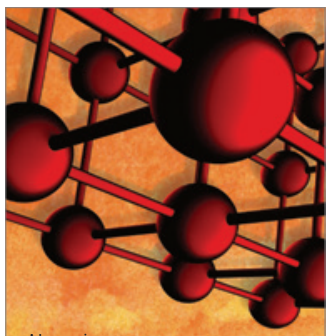

Materials Science and Engineering
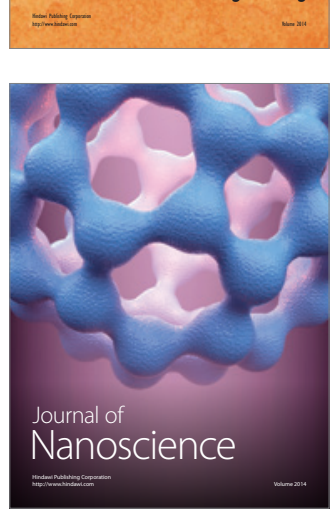
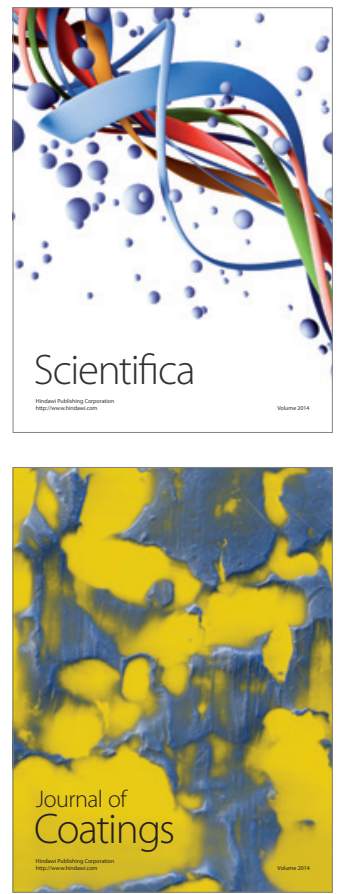
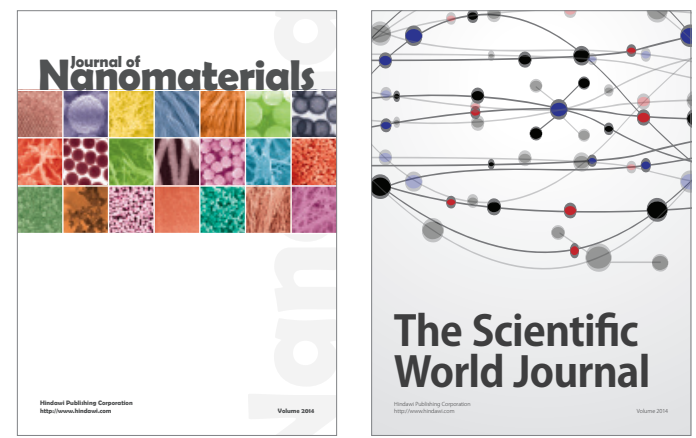

The Scientific World Journal
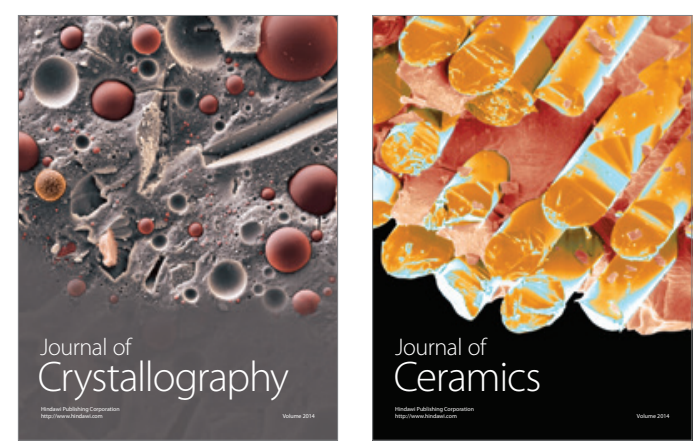
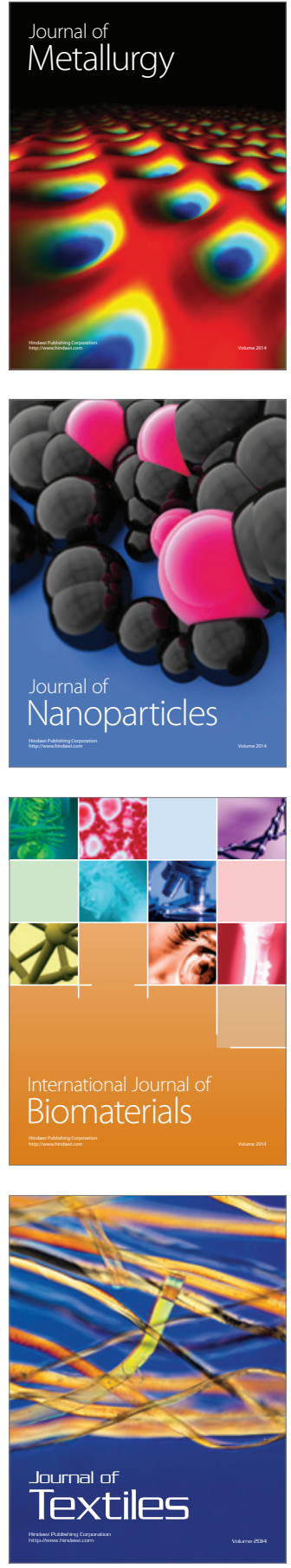